Open Peer Review on Qeios

\title{
Journalists with undisclosed conflicts mispresent research on COVID-19, confuse it with tobacco harm reduction and make false allegations about conflicts in a BMJ article
}

\author{
Konstantinos Farsalinos ${ }^{1}$
}

1 University of West Attica

Funding: The author received no specific funding for this work.

Potential competing interests: I am the author of several studies about COVID-19 and the cholinergic system, all of which were not funded by anyone. I am currently involved in a patent application concerning the use of pharmaceutical cholinergic agonists, monoclonal antibodies and diagnostic tests for COVID-19.

\section{Abstract}

A featured article in the BMJ, authored by journalists from the Investigative Desk, criticize research about COVID-19 and the cholinergic system by confusing it with tobacco harm reduction and nonpharmaceutical nicotine products. Their criticism is not based on an assessment of the studies content, analysis and presentation, but on allegations about undisclosed conflicts. I present the case that such allegations are false, and I provide documents showing that the journalists have conflicts of interest relevant to their article content that have not been disclosed. Additionally, I present evidence on the link between COVID-19 and the cholinergic system, which forms the basis for clinical trials to examine the effect of pharmaceutical cholinergic agonists in COVID-19 prevention and treatment. Despite repeatedly submitting a response, presenting the false allegations made in the article and providing documentation that the journalists have undisclosed conflicts of interest, the BMJ has not published my response. The evidence provided justifies a call for retraction of the article, the content of which should have been investigated by the BMJ before publication.

\section{Introduction}

Recently, the BMJ featured an article by journalists-members of the Investigative Desk claiming that research on COVID-19 and the cholinergic system is linked to tobacco industry and tobacco harm reduction interests to promote nicotine [1]. The journalists claim that my research on COVID-19 has been motivated by commercial tobacco and nicotine interests, and that I have not properly disclosed my conflicts of interest in my studies. The BMJ article is the last of a series of articles in news media with similar content over the past 6 months (in Le Monde and Argos-Vpro) [2,3]. In their latest article, the journalists not only repeat their allegations but they also mispresent scientific evidence about risk factors for COVID-19 and 
about the purpose and aims of my research work on COVID-19. In this article, I explain why their allegations about undisclosed conflicts are wrong, I present a short overview of my research on COVID-19, which is relevant to the cholinergic system and has nothing to do with tobacco harm reduction, and I provide evidence, through documents obtains from a Freedom of Information request, proving that the journalists have undisclosed conflicts of interest which are relevant to the content of their article. While I repeatedly submitted a response to the BMJ featured article (as a rapid response), nothing was ever published. Similarly, none of my letters to the media that published articles from The Investigative Desk journalists were ever released publicly by the media. The aim of this article is not to engage into a conflict between two parties but to restore transparency, through the presentation of undisclosed facts, and to explain the purpose and goals of research that explores the possibility that medications (cholinergic agonists) may have a therapeutic role in COVID-19. Finally, I briefly discuss the responsibility of the BMJ in featuring an article without properly investigating the accuracy of its content, and in allowing the article to still remain online despite evidence of the authors' false allegations and documented proof that the authors have undisclosed conflicts of interest.

\section{Funding and conflicts of interest}

The authors of the BMJ featured article present me as an employee of the Laboratory of Immunology and Molecular Biology of the University of Patras, and that I should have declared conflicts relevant to the activities and collaborations of the director of the Laboratory. However, they were informed through my response (dated November 21, 2020) that I do not receive a salary from the Laboratory [4]. In fact, I am a non-paid external associate at the Laboratory and that I have not received any salary, payment, remuneration, material or other forms of compensation from it. This excludes me from any conflict of interest relevant to the Laboratory and its director. Although the journalists could have independently verified this information, by asking the University or the Laboratory, and should have provided such documentation as proof for their claims, it is unclear if they made such an attempt. Additionally, I have never participated in any Laboratory project funded by commercial entities, and I am in no position to know of any agreements that the Laboratory makes with commercial or non-commercial entities. Similarly, I have no connection with, and I have not participated in any activities of the Patras Science Park and the NOSMOKE startup, which appear in the BMJ article as recipients of funding from the Foundation for a Smoke Free World.

The journalists claim that I do not present my past conflicts of interest in the studies I publish. This is a false allegation. Not only do I report all relevant conflicts and funding in full transparency in all my publications, but I also report them for far longer than the 36-months period dictated by the International Committee of Medical Journal Editors [5]. For example, funding (not "fee", as falsely mentioned by the journalists) provided by the American E-Liquid Manufacturing Standards Association (which is a non-profit association) for a research project in 2013, resulting in two publications in 2014 and 2015 [6,7], was reported not only in the relevant publications but also in several other publications and as late as 2020 ( 7 
years after the funding was received) [8]. Additionally, the meeting with the US regulators presenting results from this research project was also reported in the relevant publications $[6,7]$ but, again, no fee was received for this meeting. Finally, all my research on COVID-19 was never funded by any entity and is irrelevant to my past research on tobacco harm reduction (as I explain below).

Ironically, the authors make allegations about conflicts of interest but fail to disclose their own conflicts of interest, specifically their funding from the University of Bath and from the Bloomberg Foundation through the University of Bath. Funding from the University of Bath is disclosed in the website of the Investigative Desk [9], but not in the BMJ article or in any other article they authored [1-3]. Additionally, documents obtained through a Freedom of Information request from the University of Bath on February 5, 2021, show that not only was the Investigative Desk funded by the University $[10,11]$, but it also received funding from the Bloomberg Foundation through the University of Bath [12].

While it is unclear if the funding was provided for the specific BMJ article, one of the documents mentions “Work on the Services will be completed on: Anticipated completion end of December 2020' [11]. This coincides with a similar article authored by the Investigative Desk in a French newspaper [2]. Interestingly, the above-mentioned article in the French newspaper currently lists Stephane Horel as the only author [2]. However, that was not the case when the article was originally published. The WebAchive document dated December 19, 2020 mentions the following authors [13]: Stephane Horel, Ties Keyzer ("The Investigative Desk"), Eva Schram ("The Investigative Desk") and Harry Karanikas ("The Investigative Desk"). However, in the WebAchive document dated January 24, 2021 all journalists-members of the Investigative Desk have been removed from the authors list [14]. It is unclear whether this represents a coincidence, and no explanation was provided for this change in the authorship.

In any case, the documented funding received from the Investigative Desk represents an undisclosed conflict of interest that is relevant to the BMJ article content. It is well-known that the Bloomberg Foundation has an anti-tobacco harm reduction agenda [15-17]. It has been criticized that this agenda is not focused on research, monitoring and evaluation of proposals and strategies, as would have been expected for an evidence-based approach to a public health issue, but it includes attempts to dismiss credible and well-informed critics of their approach [16]. Additionally, I have been targeted in the past by media owned by Bloomberg because of my research on tobacco harm reduction, once again without raising any doubts about the accuracy of my research analyses and reports [18]. Therefore, the funding received by the Investigative Desk represent an undisputed, but undisclosed, conflict of interest that is relevant to the content of the BMJ featured article, since the journalists criticize research on COVID-19 by (falsely) linking it to research on tobacco harm reduction.

Notably, the authors of the featured article never questioned the accuracy of the content, analysis, presentation or interpretation of any of my studies on COVID-19. All their "criticism" is based on false allegations about conflicts of interest. However, it needs to be emphasized that in their article the journalists mispresented research findings about COVID-19 and criticize my findings, despite the fact that they have been repeatedly verified by other independent research groups. They also make false and 
misleading claims about a non-existing link between my COVID-19 research and tobacco harm reduction.

\section{Research on COVID-19 and the cholinergic system}

All the discussion about (non-existent) conflicts is irrelevant to my research on COVID-19. The latter involves a potential interaction between SARS-CoV-2 and the cholinergic system. None of my work on COVID-19 was funded by any commercial or non-commercial entity. Perhaps due to their lack of expertise, the authors of the BMJ article fail to understand the fundamental difference between this research subject and my previous and ongoing research on tobacco harm reduction and non-pharmaceutical nicotine products. My work on COVID-19 explores the possibility that pharmaceutical cholinergic agonists have a therapeutic role in preventing and/or treating the disease. This is based not only on indirect observational data about the association between smoking and COVID-19, but also on in silico experiments [19]. Observational data on smoking and COVID-19 have been reported by several research groups. OpenSafely, a dataset of primary care records of 17.3 million adults in the UK, reported that current smoking was associated with an 11\% lower chance of COVID-19 related death [20]. The authors of the BMJ article selectively presented the results of the analysis adjusting for age and sex only, but failed to present the fully-adjusted model. This may be justified due to their lack of expertise, but their statement is incorrect. OpenSafely reported that current smoking was associated with a lower risk for COVID-19 related death. Recently, a study published in the journal "Heart" (member of the BMJ Group) reported that heavy smokers were $88 \%$ less likely to be admitted to the ICU due to COVID-19, and $52 \%$ less likely to be diagnosed with COVID-19 [21]. Similarly, another study from Germany found that smokers were $72 \%$ less likely to be diagnosed with COVID-19 [22]. Several other studies from Italy, France, Israel, UK, USA, Chile and South Korea reported similar results [23-30]. All studies from different research groups verify or even expand on my findings that smokers are under-represented among hospitalized COVID-19 patients.

It should be emphasized that neither myself nor any other researcher reporting similar findings have ever suggested that smoking, one of the strongest preventable risk factors for a plethora of diseases, could ever be used for the prevention or treatment of COVID-19. Instead, this is indirect observational evidence which, combined with in silico experiments and established knowledge about the cholinergic antiinflammatory pathway, has been used to generate a hypothesis about a potential interaction between SARS-CoV-2 and the cholinergic system. My hypothesis suggests a therapeutic effect for pharmaceutical cholinergic agonists $[19,31]$. In one of my studies, I mentioned choline, nicotine, galantamine and varenicline, all of which are medications that could be studied for their role in COVID-19 due to their action as alpha 7 acetylcholine receptor agonists [19]. Such a hypothesis is biologically plausible, considering the known properties of the cholinergic anti-inflammatory pathway in modulating the immune response and the fact that severe COVID-19 is associated with a hyper-inflammatory response [31,32]. Any hypothesis that may be generated from indirect observational evidence and in vitro or in silico experiments suffers from limitations, which have been comprehensively presented in all my studies. Still, the data form the basis for conducting clinical trials with pharmaceutical cholinergic agonists, which is the only way of 
verifying or rejecting a scientific hypothesis. The authors of the featured article have obviously misunderstood my research on COVID-19, which is not surprising considering their lack of expertise; therefore, I emphasize once again that the evidence on the association between smoking and COVID-19, which has been reported by several research groups, has been used in order to generate and test a hypothesis about the potential therapeutic effects of pharmaceutical cholinergic agonists on COVID-19. Such clinical trials have been proposed by others and are already underway [33-35].

\section{Responsibility of the BMJ to investigate the article content}

It is unclear if the BMJ investigated the accuracy of journalists' claims before releasing the article. It is also unknown if the article was peer-reviewed. I was never contacted by any member of the BMJ staff in order to provide my views and to respond to the content of the article before it was published. It is unclear if they investigated the authors' funding sources and conflicts of interest. However, I have repeatedly contacted the BMJ (including the editor) and I have submitted my response online several times (as a rapid response), including all documentation about the journalists' undisclosed conflicts of interest. The BMJ have also received (in a separate email) all relevant documents that were obtained through a Freedom of Information request [36]. Still, my response was never published, while the featured article remains online, even today, without any reference to the authors' conflicts of interest and without any correction about the false content and allegations. This raises questions about the motives and the publication standards of the $\mathrm{BMJ}$, considering that the journal is expected to be liable for any false and inaccurate content they publish online. While it is understandable that the BMJ may need to further investigate my response and the documents I provided, they should have exercised similar caution and responsibility before publishing the journalists' featured article, and they should have retracted the article while investigating my response. Instead, they have allowed the article to be available online and to remain unanswered.

\section{Conclusion}

In conclusion, journalists with undisclosed conflicts of interest made an effort to discredit research for COVID-19 by confusing such research with tobacco harm reduction, and by making allegations about conflicts of interest that are not only false but also irrelevant to COVID-19 research. The latter was not funded by any entity. They also mispresented published evidence about the association between risk factors and COVID-19. It is concerning that the BMJ featured article still remains online and unanswered, considering that the BMJ is responsible and liable for the allegations made by the journalists. Such actions may discourage other scientists from accurately presenting research findings, due to fear that they may be the subject of similar false allegations. It is important that research on COVID-19 prevention and treatment continues, and current evidence forms the basis for conducting clinical trials to evaluate the potential effect of cholinergic agonists on COVID-19 susceptibility and severity.

\section{Statement on Competing Interests.}


I am the author of several studies about COVID-19 and the cholinergic system, all of which were not funded by anyone. I am currently involved in a patent application concerning the use of pharmaceutical cholinergic agonists, monoclonal antibodies and diagnostic tests for COVID-19.

\section{References}

1. Horel S, Keyzer T. Covid 19: How harm reduction advocates and the tobacco industry capitalised on the pandemic to promote nicotine. BMJ. 2021 Jun 2;373:n1303. doi: 10.1136/bmj.n1303.

2. Le Monde. Petites ficelles et grandes manœuvres de l'industrie du tabac pour réhabiliter la nicotine. Available at: https://www.lemonde.fr/planete/article/2020/12/19/petites-ficelles-et-grandes-man-uvresde-l-industrie-du-tabac-pour-rehabiliter-la-nicotine_6063922_3244.html. Accessed on June 9, 2021.

3. Argos-Vpro. Tabaksindustrie grijpt Covid-19 aan om nicotine te promoten. Available at: https://www.vpro.nl/argos/lees/onderwerpen/tabak/2020/tabaksindustrie-grijpt-covid-19-aan-omnicotine-te-promoten.html. Accessed on June 16, 2021.

4. Farsalinos K. Personal communication by email with a member of The Investigative Desk. November 21, 2020. Available at: https://tinyurl.com/bx5x3xjk.

5. International Committee of Medical Journal Editors. Disclosure of Interest (Updated February 2021). Available at: http://www.icmje.org/downloads/coi_disclosure.docx.

6. Farsalinos KE, Spyrou A, Tsimopoulou K, Stefopoulos C, Romagna G, Voudris V. Nicotine absorption from electronic cigarette use: comparison between first and new-generation devices. Sci Rep. 2014 Feb 26;4:4133. doi: 10.1038/srep04133.

7. Farsalinos KE, Spyrou A, Stefopoulos C, Tsimopoulou K, Kourkoveli P, Tsiapras D, Kyrzopoulos S, Poulas K, Voudris V. Nicotine absorption from electronic cigarette use: comparison between experienced consumers (vapers) and naïve users (smokers). Sci Rep. 2015 Jun 17;5:11269. doi: 10.1038/srep11269. Erratum in: Sci Rep. 2015;5:13506.

8. Farsalinos KE, Barbouni A. Association between electronic cigarette use and smoking cessation in the European Union in 2017: analysis of a representative sample of 13057 Europeans from 28 countries. Tob Control. 2021 Jan;30(1):71-76. doi: 10.1136/tobaccocontrol-2019-055190.

9. The Investigative Desk. Funding and Independence. Available at: https://investigativedesk.com/about/.

10. University of Bath. New Supplier Application Form. Available at: https://tinyurl.com/45sz779n. Document obtained through a Freedom of Information Act request.

11. University of Bath. Contract for Services Schedule. Available at: https://tinyurl.com/dts3hcp3. Document obtained through a Freedom of Information Act request.

12. University of Bath. Reference: New Supplier Form for Investigative Desk. Available at: https://tinyurl.com/h9f8h5ht. Document obtained through a Freedom of Information Act request.

13. Le Monde. Petites ficelles et grandes manœuvres de l'industrie du tabac pour réhabiliter la nicotine. Available at:

https://web.archive.org/web/20201219060527/https://www.lemonde.fr/planete/article/2020/12/19/petites- 
ficelles-et-grandes-man-uvres-de-I-industrie-du-tabac-pour-rehabiliter-la-nicotine_6063922_3244.html (archive dated December 19, 2020).

14. Le Monde. Petites ficelles et grandes manœuvres de l'industrie du tabac pour réhabiliter la nicotine. Available at:

https://web.archive.org/web/20210124212446/https://www.lemonde.fr/planete/article/2020/12/19/petitesficelles-et-grandes-man-uvres-de-l-industrie-du-tabac-pour-rehabiliter-la-nicotine 6063922 3244.html (archive dated January 24, 2021).

15. Gunther M. Bloomberg's Millions Funded an Effective Campaign Against Vaping. Could It Do More Harm Than Good? The Chronicle of Philanthropy. Available at:

https://www.philanthropy.com/article/bloombergs-millions-funded-an-effective-campaign-againstvaping-could-it-do-more-harm-than-good.

16. Clive Bates. Holding the Bloomberg anti-vaping propaganda complex to account. Available at: https://www.clivebates.com/holding-the-bloomberg-anti-vaping-propaganda-complex-to-account/.

17. Burning Issues: The Global State of Tobacco Harm Reduction 2020. Available at:

https://gsthr.org/resources/item/burning-issues-global-state-tobacco-harm-reduction-2020.

18. Bloomberg. Scientists Are Working Overtime to Debunk the Vaping Scare. Available at: https://www.bloomberg.com/news/features/2019-10-31/is-vaping-safe-scientists-disagree-on-health-ofe-cigs-like-juul.

19. Farsalinos K, Eliopoulos E, Leonidas DD, Papadopoulos GE, Tzartos S, Poulas K. Nicotinic Cholinergic System and COVID-19: In Silico Identification of an Interaction between SARS-CoV-2 and Nicotinic Receptors with Potential Therapeutic Targeting Implications. Int J Mol Sci. 2020 Aug 13;21(16):5807. doi: 10.3390/ijms21165807.

20. Williamson EJ, Walker AJ, Bhaskaran K, Bacon S, Bates C, Morton CE, Curtis HJ, Mehrkar A, Evans D, Inglesby P, Cockburn J, McDonald HI, MacKenna B, Tomlinson L, Douglas IJ, Rentsch CT, Mathur R, Wong AYS, Grieve R, Harrison D, Forbes H, Schultze A, Croker R, Parry J, Hester F, Harper S, Perera R, Evans SJW, Smeeth L, Goldacre B. Factors associated with COVID-19-related death using OpenSAFELY. Nature. 2020 Aug;584(7821):430-436. doi: 10.1038/s41586-020-2521-4.

21. Hippisley-Cox J, Tan PS, Coupland C. Risk of severe COVID-19 disease with ACE inhibitors and angiotensin receptor blockers: cohort study including 8.3 million people. Heart. 2020 Nov 5:heartjnl2020-318312. doi: 10.1136/heartjnl-2020-318312.

22. Kowall B, Nonnemacher M, Brune B, Brinkmann M, Dudda M, Böttcher J, Schmidt B, Standl F, Stolpe S, Dittmer $\mathrm{U}$, Jöckel KH, Stang A. A model to identify individuals with a high probability of a SARS-CoV-2 infection. J Infect. 2021 Mar;82(3):e32-e34. doi: 10.1016/j.jinf.2020.11.028.

23. Rossato M, Russo L, Mazzocut S, Di Vincenzo A, Fioretto P, Vettor R. Current smoking is not associated with COVID-19. Eur Respir J. 2020 Jun 4;55(6):2001290. doi: 10.1183/13993003.01290-2020.

24. Docherty AB, Harrison EM, Green CA, Hardwick HE, Pius R, Norman L, Holden KA, Read JM, Dondelinger F, Carson G, Merson L, Lee J, Plotkin D, Sigfrid L, Halpin S, Jackson C, Gamble C, Horby PW, Nguyen-Van- 
Tam JS, Ho A, Russell CD, Dunning J, Openshaw PJ, Baillie JK, Semple MG; ISARIC4C investigators. Features of 20133 UK patients in hospital with covid-19 using the ISARIC WHO Clinical Characterisation Protocol: prospective observational cohort study. BMJ. 2020 May 22;369:m1985. doi: 10.1136/bmj.m1985.

25. Fontanet A, Tondeur L, Madec Y, Grant R, Besombes C, Jolly N, Pellerin SF, Ungeheuer MN, Cailleau I, Kuhmel L, Temmam S, Huon C, Chen KY, Crescenzo B, Munier S, Demeret C, Grzelak L, Staropoli I, Bruel T, Gallian P, Cauchemez S, van der Werf S, Schwartz O, Eloit M, Hoen B. Cluster of COVID-19 in northern France: A retrospective closed cohort study. medRxiv 2020.04.18.20071134; doi: https://doi.org/10.1101/2020.04.18.20071134.

26. Israel A, Feldhamer I, Lahad A, Levin-Zamir D, Lavie G. Smoking and the risk of COVID-19 in a large observational population study. medRxiv 2020.06.01.20118877; doi: https://doi.org/10.1101/2020.06.01.20118877.

27. Iruretagoyena M, Vial MR, Spencer-Sandino M, Gaete P, Peters A, Delgado I, Perez I, Calderon C, Porte L, Legarraga P, Anderson A, Aguilera X, Vial P, Weitzel T, Munita JM. Longitudinal assessment of SARS-CoV2 IgG seroconversionamong front-line healthcare workers during the first wave of the Covid-19 pandemic at a tertiary-care hospital in Chile. BMC Infect Dis. 2021 May 26;21(1):478. doi: 10.1186/s12879-021-06208-2.

28. Petrilli CM, Jones SA, Yang J, Rajagopalan H, O'Donnell L, Chernyak Y, Tobin KA, Cerfolio RJ, Francois F, Horwitz LI. Factors associated with hospital admission and critical illness among 5279 people with coronavirus disease 2019 in New York City: prospective cohort study. BMJ. 2020 May 22;369:m1966. doi: 10.1136/bmj.m1966.

29. Jose T, Croghan IT, Hays JT, Schroeder DR, Warner DO. Electronic Cigarette Use Is Not Associated with COVID-19 Diagnosis. J Prim Care Community Health. 2021 Jan-Dec;12:21501327211024391. doi: $10.1177 / 21501327211024391$.

30. Lee SC, Son KJ, Kim DW, Han CH, Choi YJ, Kim SW, Park SC. Smoking and the risk of severe acute respiratory syndrome coronavirus 2 (SARS-CoV-2) infection. Nicotine Tob Res. 2021 Apr 23:ntab079. doi: 10.1093/ntr/ntab079.

31. Farsalinos K, Niaura R, Le Houezec J, Barbouni A, Tsatsakis A, Kouretas D, Vantarakis A, Poulas K. Editorial: Nicotine and SARS-CoV-2: COVID-19 may be a disease of the nicotinic cholinergic system. Toxicol Rep. 2020 Apr 30;7:658-663. doi: 10.1016/j.toxrep.2020.04.012.

32. Tracey KJ. The inflammatory reflex. Nature. 2002 Dec 19-26;420(6917):853-9. doi: $10.1038 /$ nature01321.

33. ClinicalTrials.gov. Efficacy of Nicotine in Preventing COVID-19 Infection (NICOVID-PREV). Available at: https://clinicaltrials.gov/ct2/show/NCT04583410.

34. ClinicalTrials.gov. Evaluation of the Efficacy of Nicotine Patches in SARS-CoV2 (COVID-19) Infection in Intensive Care Unit Patients (NICOVID-REA). Available at: https://clinicaltrials.gov/ct2/show/NCT04598594. 
35. Ahmad F. COVID-19 induced ARDS, and the use of galantamine to activate the cholinergic antiinflammatory pathway. Med Hypotheses. 2020 Dec;145:110331. doi: 10.1016/j.mehy.2020.110331.

36. Freedom of Information Request 012/21, University of Bath. Documents obtained through a Freedom of Information request concerning agreements, contracts and memoranda between the University of Bath, Bloomberg Philanthropies and the Investigative Desk. Available at: https://tinyurl.com/288a59dn. 